\title{
CASE REPORT ON DOCETAXEL-INDUCED INTERSTITIAL LUNG DISEASE
}

\author{
REMYA ANTONY ${ }^{1}$, SHIVA KRISHNA ${ }^{1}$, JINI JAMES ${ }^{1}$, AKHILESH KUNOOR ${ }^{2}$, MEENU VIJAYAN ${ }^{*}$
}

${ }^{1}$ Department of Pharmacy Practice, Amrita School of Pharmacy, Kochi, Amrita Vishwa Vidyapeetham, Amrita University, India. ${ }^{2}$ Department of Pulmonary Medicine, Amrita Institute of Medical Sciences, Kochi, Amrita Vishwa Vidyapeetham, Amrita University, India. Email: meenuvijayan@aims.amrita.edu

Received: 09 April 2017, Revised and Accepted: 05 July 2017

ABSTRACT

Docetaxel belongs to taxane family of antineoplastic agents that are indicated for the treatment of locally advanced or metastatic non-small-cell lung cancer. Docetaxel is associated with many adverse effects, and pulmonary reaction has an incidence of $41 \%$. However, interstitial pulmonary disease is found to occur only in $<1 \%$ of the population as per the post-marketing surveillance reports. Here, we report a case of docetaxel-induced interstitial lung disease (ILD). The patient information and details were collected using the hospital information system. The adverse drug reaction (ADR) of ILD occurred after 5 cycles of chemotherapy with docetaxel at a dose of $60 \mathrm{mg} / \mathrm{m}^{2}$ that is $80 \mathrm{mg}$ IV. The causality of the event in our case was assessed using the Naranjo ADR probability scale which marked a score of 7 (probable). It is necessary that all physicians be aware of the reaction and to closely monitor clinicoradiological and functional status of the patients at regular intervals after administration of docetaxel.

Keywords: Docetaxel, Interstitial lung disease, Naranjo adverse drug reaction probability scale.

(C) 2017 The Authors. Published by Innovare Academic Sciences Pvt Ltd. This is an open access article under the CC BY license (http://creativecommons. org/licenses/by/4. 0/) DOI: http://dx.doi.org/10.22159/ajpcr.2017.v10i10.19043

\section{INTRODUCTION}

Interstitial lung disease (ILD) is a group of diseases affecting the interstitium which is a delicate, thin lining between the lung's alveoli that contain the blood vessels for gas exchange between the alveoli [1]. Docetaxel belongs to the taxane family of antineoplastic agents that are indicated for the treatment of locally advanced or metastatic breast cancer, locally advanced or metastatic non-small-cell lung cancer, hormone refractory prostate cancer, gastric adenocarcinoma, and squamous cell carcinoma of the head and neck cancer [2]. The extract of the European yew, Taxus baccata is the source from where docetaxel is being derived [3]. It is commonly sold under the brand name Taxotere.

The anticancer properties of docetaxel are by promoting tubulin assembly thus forming stable microtubules and by inhibiting tubulin depolymerization which leads to stabilization of microtubules in the cell. This inturn inhibits protein, deoxyribonucleic acid, and ribonucleic acid synthesis leading to the arrest of cell mitosis in the M phase of cell cycle. Since docetaxel is known to prevent the depolymerization of microtubules, it is cytotoxic against human ovarian, endometrial, colon, and breast cancer. When compared with insoluble paclitaxel, docetaxel which is soluble shows more cytotoxicity [4]. The most common adverse events $(>10 \%)$ associated with docetaxel include fluid retention, alopecia, central nervous system reactions (neuropathy), dermatological reactions, stomatitis, nausea, vomiting, diarrhoea, elevated serum transaminases, neutropenia, thrombocytopenia, leukopenia, anemia, myalgia, neuromuscular reaction, nail disease and pulmonary reaction. Pulmonary reactions associated with docetaxel are found to be approximately $41 \%$. Among the pulmonary reactions, interstitial pulmonary disease is found to occur only in $<1 \%$ of the population as per the post-marketing surveillance reports. Here, we report the case of ILD after 5 cycles of chemotherapy with docetaxel which is a rare adverse effect of the drug.

\section{CASE REPORT}

A 34-year-old female who is a known case of carcinoma breast with bone marrow metastasis and adnexal mass under evaluation presented to Pulmonary Medicine Department with complaints of grade 2 dyspnea of 2-week duration and dry cough. She was on chemotherapy with Docetaxel $\left(60 \mathrm{mg} / \mathrm{m}^{2}\right.$ that is $80 \mathrm{mg}$ IV) - completing 5 cycles and the $5^{\text {th }}$ cycle being completed 9 days before the presentation. On examination, the patient had basal crepitations, and a chest X-ray was taken which showed bilateral reticulonodular shadows with right sided pleural effusion (Fig. 1), In view of pleural effusion, chemotherapy with docetaxel was discontinued.

Positron emission tomography (PET)/computed tomography (CT) images in the previous month (Fig. 2) as discussed with nuclear medicine and radiology consultants showed moderate bilateral pleural effusion but no evidence of ILD.

Pulmonary function test (PFT) done showed severe restriction (Table 1) and diffusing capacity for carbon monoxide showed severe reduction. The 6 minutes' walk test (6MWT) examination indicated Grade 5 dyspnea. CT thorax Fig. 3 was done which showed bilateral pleural effusion with mild ground-glass opacity on bilateral lung parenchyma indicative of ILD. Pleural fluid aspiration was done and sends for cytology tests. Cytology revealed exudative effusion with low adenosine deaminase, negative for malignancy.

As the patient had significant effort intolerance, exercise-induced severe desaturation, and radiological evidence of ILD, she was initiated on systemic steroids for the next 10 days along with a course of antibiotics for 1 week (tab cefpodoxime $200 \mathrm{mg}$ 1-0-1*1 week). After 10 days steroid therapy, patient symptomatically improved with good effort tolerance. Repeat chest X-ray showed left shallow pneumothorax, and PFT indicated mild improvement (Table 1). Distance covered in the 6MWT increased to $420 \mathrm{~m}(99-81 \%)$ from $240 \mathrm{~m}$ and further increased on a later date (Table 1).

As the patient had subjective and clinical improvement (Table 1) with systemic steroids, she was planned to be kept under close follow-up with oral steroids (tab prednisolone $40 \mathrm{mg}$ for 1 week and later $30 \mathrm{mg}$ 1-0-0 for the next 1 week). Chest X-ray after 2 week showed reduction in the interstitial shadow with complete resolution of pneumothorax (Fig. 4). She was advised to continue oral steroids in tapering doses depending on the functional and clinicoradiological improvement and was initiated on tamoxifen for cancer management. 


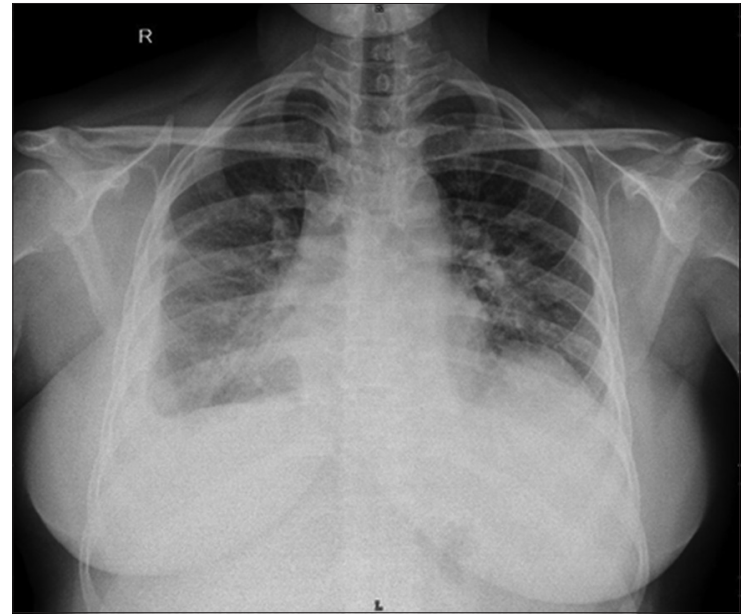

Fig. 1: Chest X-ray after 5 cycles of docetaxel administration

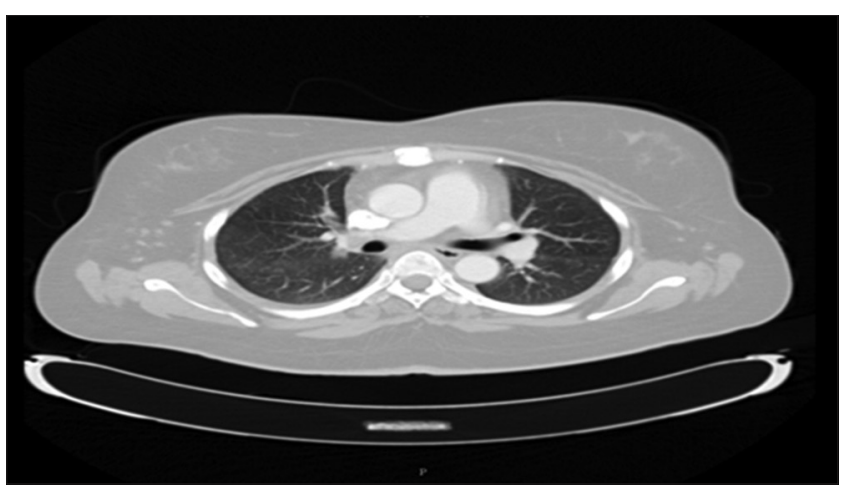

Fig. 2: Computed tomography taken before docetaxel therapy showing clear lung fields

\section{DISCUSSION}

Docetaxel/paclitaxel in combination with trastuzumab is now considered as the first-line treatment for tumors with human epidermal growth factor receptor 2 over expression, that is, for patients with metastatic disease who have not taken chemotherapy [5]. Our patient was on docetaxel monotherapy. On reviewing the side effect profile of the drug, the incidence of docetaxel-inducing interstitial pulmonary disease is $<1 \%$ and thus the occurrence of docetaxel-induced ILD is rare. However, recently many case reports concerning this reaction have been published. The proposed mechanism by which taxanes are known to cause pulmonary toxicity is by:

- Promotion of cytotoxic T-cell proliferation causing a hypersensitivity type of reaction leading to lung damage,

- Promotion of reactive oxygen metabolites causing direct pulmonary damage.

As demonstrated in our case report, the reaction responds to drug discontinuation and steroid therapy. However, if the treatment is delayed, it can even lead to respiratory failure [6].

The docetaxel-induced ILD usually occurred after the second to the fourth course of chemotherapy and was usually relieved by corticosteroid therapy [7]. However, in our case, interstitial features were exhibited after the $5^{\text {th }}$ course of docetaxel which may be due to the concomitant steroid therapy given to the patient.

Wang et al. reported a case of pulmonary toxicity of ILD which developed 3 days after docetaxel therapy. The reaction was confirmed by diffuse interstitial infiltrates in the chest X-ray and diffuses ground glass opacities in bilateral lung fields in chest CT [6]. The dose was reported to be $30 \mathrm{mg} / \mathrm{m}^{2}$ which is relatively a low dose when compared

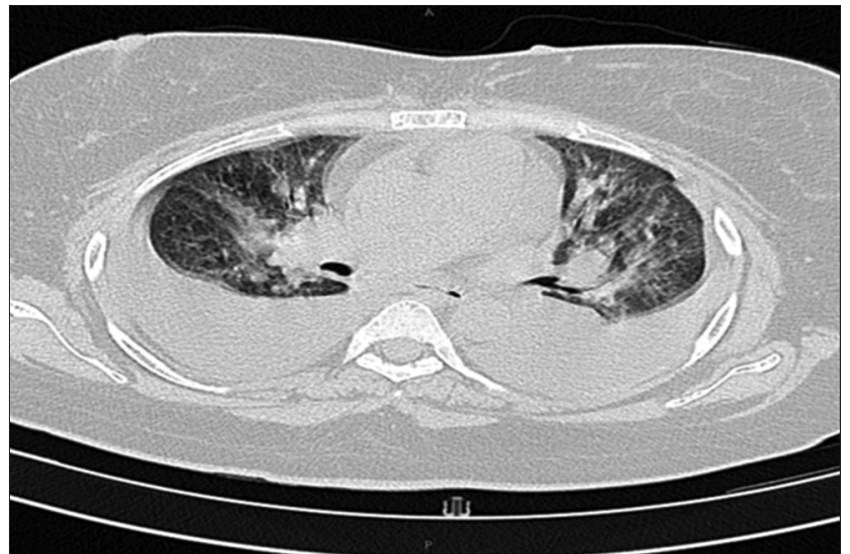

Fig. 3: Computed tomography showing ground glass opacities and pleural effusion after $\mathbf{5}$ cycles of docetaxel therapy

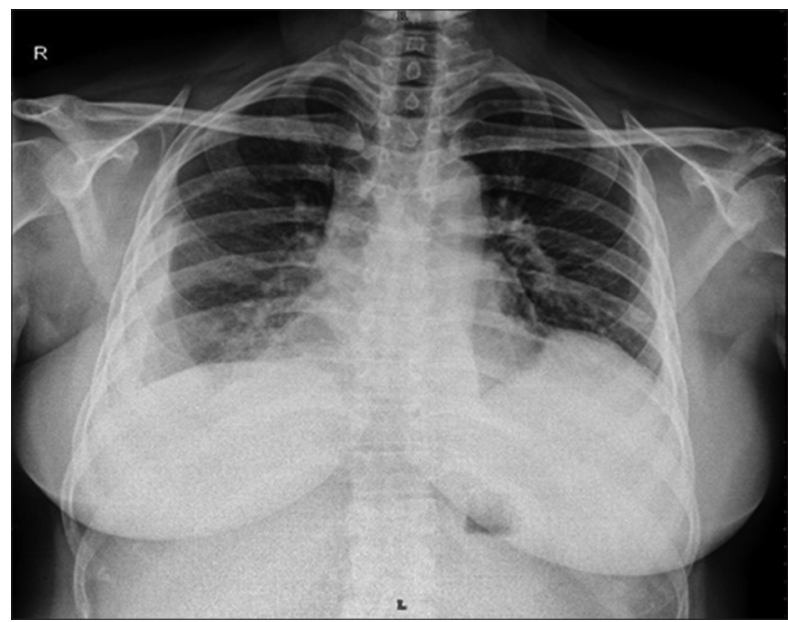

Fig. 4: Chest X-ray showing reduced reticulonodular shadows after steroid therapy

Table 1: Comparison of laboratory parameters - after 5 cycles of docetaxel therapy versus on discontinuation of docetaxel therapy and initiation of steroid therapy

\begin{tabular}{|c|c|c|}
\hline Parameters & $\begin{array}{l}\text { After } 5 \text { cycles of } \\
\text { docetaxel therapy }\end{array}$ & $\begin{array}{l}\text { On discontinuation of } \\
\text { docetaxel therapy and } \\
\text { initiation of steroid } \\
\text { therapy }\end{array}$ \\
\hline FEV1 & $24.2-24.7$ & $29.0-29.0$ \\
\hline FVC & $21.8-22.5$ & $25.6-26.3$ \\
\hline 6MWT & $\begin{array}{l}\mathrm{SpO}_{2} \text { reduced from } 96 \% \\
\text { to } 79 \% \text { after covering a } \\
\text { distance of } 240 \mathrm{~m}\end{array}$ & $\begin{array}{l}\mathrm{SpO}_{2} \text { reduced from } 98 \% \\
\text { to } 82 \% \text { after covering a } \\
\text { distance of } 440 \mathrm{~m}\end{array}$ \\
\hline
\end{tabular}

FEV1: Forced expiratory volume in 1s, FVC: Forced expiratory vital capacity, 6MWT: 6 minutes' walk test

to the dose in our case $\left(60 \mathrm{mg} / \mathrm{m}^{2}\right)$ which indicates that even a low dose can cause a significant reaction. This also suggests that the incidence of ILD is not dose related.

Studies indicate that patients on a weekly schedule of docetaxel are more vulnerable to pneumonitis than patients on triweekly schedule. However, weekly schedule of docetaxel reported lower incidence of myelosuppression when compared to triweekly schedule indicating that the incidence of pulmonary toxicity is more related to the delivery schedule of docetaxel rather than its dose [3,8-10]. However, in our case, the patient developed pneumonitis despite the adoption of triweekly 
administration schedule of docetaxel thus a more keen monitoring of the patients should be conducted even if they are on a triweekly dosing schedule.

Storaas et al. also reported a case of a breast cancer patient who developed pneumonitis during docetaxel therapy which was severe and progressive in nature. The reaction was observed after four courses of twice weekly schedule of I.V. docetaxel $100 \mathrm{mg} / \mathrm{m}^{2}$ and was found to be steroid resistant. The pneumonitis was worsened by other complications such as severe hypercapnia and hypoxia, bilateral pneumothorax, and reduced lung compliance because of which the patient died in the intensive care unit after 20 days of advanced ventilator supports [8].

The largest series of docetaxel associated interstitial pneumonitis was published by Tamiya et al. which consisted of 392 patients with metastatic non-small-cell lung cancer, of which 18 cases of ILD were reported with tri-weekly schedule of a higher dose of docetaxel $\left(75 \mathrm{mg} / \mathrm{m}^{2}\right)$ thus marking an incidence of $4.6 \%$. The study suggested that approximately 10-20 days, that is, a median time of 18 days was the time elapse from the last docetaxel administration to the onset of toxicity findings on the chest X-ray [11]. For our patient, the time taken for the onset of toxicity after the last docetaxel administration was approximately 9 days which is slightly contrary to the above study findings.

Another case series reported 4 cases of ILD within 8-14 days of receiving a second or third cycle of docetaxel followed by progression into respiratory failure that required mechanical ventilation. The symptoms were insidious in onset the reaction was not responding to broad spectrum antibiotics and corticosteroids and 2 patients died of pulmonary complications whereas the other 2 required more than 3 week of ventilatory support. This study also establishes ILD as a complication of docetaxel treatment even after rendering corticosteroid premedication. The study concludes that aggressive pulmonary support can be provided for the management of such reactions if the patient is having a favorable prognosis.

A life-threatening ILD requiring ventilator support after docetaxel therapy (NSCLC) was reported in 4 patients with advanced non-smallcell lung cancer [3]. Even though docetaxel was administered as an infusion within $1 \mathrm{hr}$ at a dose of $30-60 \mathrm{mg} / \mathrm{m}^{2}$ after giving the standard premedication, one among the 4 patients was diagnosed to have ILD 5 days after the $1^{\text {st }}$ cycle of docetaxel, and for the other 3 , between the $2^{\text {nd }}$ and $6^{\text {th }}$ cycles.

The causality of the event in our case was assessed using the Naranjo adverse drug reaction probability scale which marked a score of 7
(Probable). Due to the inherent risk and severity of the reaction, a rechallenge could not be performed. Docetaxel therapy was discontinued upon which the patient's condition improved and the patient was initiated on tamoxifen.

\section{CONCLUSION}

Our case report once again demonstrates the occurrence of ILD after docetaxel administration. Measures which can be taken to reduce the incidence of this reaction include premedication with high dose steroid therapy 3 days before initiation of docetaxel therapy, administration of concomitant steroid therapy during docetaxel therapy and choosing a triweekly dosing schedule. It is necessary that all physicians be aware of the reaction and to closely monitor clinicoradiological and functional status of the patients at regular intervals after administration of docetaxel.

\section{REFERENCES}

1. Ragaa I. Tropical parasitic lung diseases. Int J Pharm Pharm Sci 2015;7(5):2-12.

2. Fauzee NJ, Dong Z, Wang YL. Taxanes: Promising anti-cancer drugs. Asian Pac J Cancer Prev 2011;12(4):837-51.

3. Wang GS, Yang KY, Perng RP. Life-threatening hypersensitivity pneumonitis induced by docetaxel (taxotere). $\mathrm{Br} \mathrm{J}$ Cancer 2001;85(9):1247-50.

4. Bonde S, Nair S. Advances in liposomal drug delivery system: Fascinating types and potential applications. Int $\mathrm{J}$ Appl Pharm 2017;9(3):1-7.

5. De Souza Bandeira TF, Mozegui GB, De Mello Vianna CM, Araujo RL, Da Silva Rodrigues MP, Do Valle PM. Cost-effectiveness analysis of trastuzumab in the treatment of metastatic breast cancer. Int J Pharm Pharm Sci 2015;7(4):307-12.

6. Wang CJ, Chang HT, Chang CY. Docetaxel-related interstitial pneumonitis. Ther Clin Risk Manag 2015;11:1813-6.

7. Min BD, Kang HW, Kim WT, Kim YJ, Yun SJ, Lee SC, et al. Docetaxelinduced fatal interstitial pneumonitis in a patient with castrationresistant prostate cancer. Korean J Urol 2012;53(5):371-4

8. Storaas E, Holmaas G, Gravdal K, Børretzen A, Eikesdal HP. Lethal pneumonitis after docetaxel chemotherapy: Case report and review of the literature. Acta Oncol 2013;52(5):1034-8.

9. Read WL, Mortimer JE, Picus J. Severe interstitial pneumonitis associated with docetaxel administration. Cancer 2002;94(3):847-53.

10. Chen YM, Shih JF, Perng RP, Tsai CM, Whang-Peng J. A randomized trial of different docetaxel schedules in non-small cell lung cancer patients who failed previous platinum-based chemotherapy. Chest 2006;129(4):1031-8.

11. Tamiya A, Naito T, Miura S, Morii S, Tsuya A, Nakamura Y, et al. Interstitial lung disease associated with docetaxel in patients with advanced non-small cell lung cancer. Anticancer Res 2012;32(3):1103-6. 